\title{
Progress on Defining the CEAB Graduate Attributes at Carleton University
}

\author{
Jessica Harris \\ Graduate Attributes Coordinator \\ Faculty of Engineering \& Design \\ Carleton University \\ jessica_harris@carleton.ca
}

\author{
Alan Steele, Ph.D., P.Eng \\ Associate Professor \\ Department of Electronics \\ Carleton University \\ asteele@doe.carleton.ca
}

\author{
Donald Russell, Ph.D., P.Eng. (N.S.) \\ Professor \& Associate Dean \\ Faculty of Engineering \& Design \\ Carleton University \\ drussell@mae.carleton.ca
}

\begin{abstract}
The Canadian Engineering Accreditation Board $(C E A B)$ is requiring engineering programs to demonstrate that their graduating students have certain specified attributes beginning in 2014. At Carleton University we have been working on developing our approaches to meeting this requirement for some time. This paper presents some of the aspects of our efforts that appear to be unique.

It was important to include in the process coverage of the Ontario government's Undergraduate Degree Level Expectations (UDLEs). After reviewing the UDLEs we created what we are describing as a thirteenth Graduate Attribute - Limits of Knowledge. With the establishment of this attribute both the CEAB and UDLE requirements are covered with a single process.

Considerable effort was given to the process for defining competencies (specific and measurable criteria associated with each of the broad attributes) in a clear and functional manner.

Our process separates each competency into three components: area of knowledge, expectation levels and context. The area of knowledge is a noun phrase that clearly describes the specific aspect of the graduate attribute to be measured. The expectation levels include both threshold and target specifications using the revised Bloom's Taxonomy as a cognitive hierarchy. The final component of each competency is the context which allows each discipline to specify a possibly unique area of application.
\end{abstract}

\section{Background}

University is about education. Engineering education in Canada is primarily guided by The Canadian Engineering Accreditation Board (CEAB), provincial governments and faculty desires. There are changes occurring within both the CEAB and the Province (in Ontario). The focus is changing toward learning objectives, and more importantly, learning outcomes.

"The CEAB was established by Engineers Canada in 1965 to accredit undergraduate engineering programs that provide the academic requirements necessary for licensure as a professional engineer in Canada." [1]

Two goals of the CEAB are to ensure that engineering programs meet educational standards and that these programs are continually improving, both in quality and applicability to the ever-changing world. [2]

The previous requirements of accreditation were largely based on curriculum content. This way of thinking about engineering education is in terms of inputs. Inputs include not only course content, but also such things as campus resources, laboratory equipment, faculty education and support services. It is assumed that the inputs provided to students will generate specific outcomes (certain knowledge and skills). With outcomes-based assessment, the CEAB is not depending on these assumptions.

The new requirement, entitled "graduate attributes," is focused on outcomes: students' ability to demonstrate the knowledge and skills they have learned. In other words, outcomes assessment 
identifies what students have learned as compared to what they have been taught.

Most engineering accreditation bodies, including Accreditation Board for Engineering and Technology (ABET) [3], Engineers Australia [4], and the Engineering Accreditation Board (Engineering Council in the UK) [5] already use outcomes-based assessment. Outcomes-based assessment is also widely used in primary and secondary schools in Canada, as well as at colleges.

The accreditation criteria [2] are as follows:

“3.0 Continual Improvement: Engineering programs are expected to continually improve. There must be processes in place that demonstrate that program outcomes are being assessed in the context of the graduate attributes, and that the results are applied to the further development of the program.

3.1 Graduate Attributes: The institution must demonstrate that the graduates of a program possess the attributes under the following headings. The attributes will be interpreted in the context of candidates at the time of graduation. It is recognized that graduates will continue to build on the foundations that their engineering education has provided."

This is a work in progress; the CEAB has only given these guidelines, and is not dictating the details, nor specifying the requirements on how to measure the attributes. This gives universities the freedom to tailor the response to their own needs.

In addition, The Ontario Council of Academic Vice Presidents (OCAV) adopted the Undergraduate Degree-Level Expectations (UDLEs) in 2005 [6], and they were to be implemented across Ontario universities by 2008. UDLEs are the learning outcomes expected for students who graduate with undergraduate degrees in all disciplines from Ontario universities.

York University compiled a list of reasons why UDLEs are necessary [7], including these:

- "helps faculty members design courses that align with overall program goals

- informs students of the expectations and standards of the program

- provides a framework for evaluating the effectiveness of the program

- provides concrete evidence of the quality of a program"

This paper details our approach to meeting the new requirements set forth by the $\mathrm{CEAB}$ while ensuring we also meet the requirements of the UDLEs.

\section{Approach}

At Carleton University, we have decided to come up with a set of attributes that incorporate both the graduate attributes set forth by the CEAB and OCAV's UDLEs. This way, we can be sure to save valuable time by not duplicating work, while being thorough at the same time.

The viewpoint of learning outcomes is fairly new to the bulk of engineering educators. This project is a rather large undertaking and requires substantial effort. As an institution, we have made the decision to dedicate one full time position to this process, a Graduate Attributes Coordinator.

We have put together a Graduate Attributes Committee consisting of the Associate Dean of Policy and Planning, the Associate Dean of Student Affairs, the chair and associate chair from each engineering department, a representative from Quality Assurance, and our Graduate Attributes Coordinator. The committee meets regularly to work on this project and discuss progression. The reason for this large group is so that we can have faculty buy-in, broad support, as much input as possible, and assistance with putting the new measures into place.

In regards to a timeline, our intent is to have completed our planning phase by September 2011, establish measurements for attributes and collect preliminary data during the 2011-2012 academic year, and begin collecting comprehensive data by September 2012. The CEAB will be assessing this section of requirements beginning in 2014. Please see Figure 1 below.

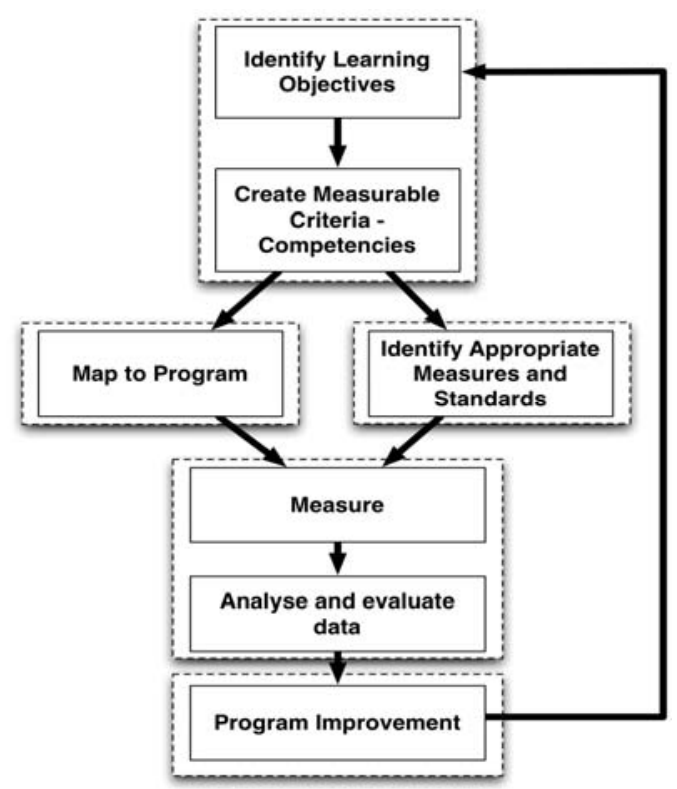

Figure 1. Graduate attribute process 


\section{Progress}

We focused on two main areas, the first being the merging of the CEAB graduate attributes and the OCAV UDLEs.

\subsection{Graduate attributes}

In comparing the criteria for each of the two requirements (graduate attributes and UDLEs), it can be determined that there is much overlap. (See Figure 2.) The graduate attributes are a more complete list, but there are 3 UDLEs that are not explicitly covered.

UDLE \#1 (Depth and Breadth of Knowledge) consists of several criteria, each identified by a letter.

The three UDLEs that we did not see clearly in the graduate attributes are:

1b) A developed understanding of many of the major fields in a discipline, including, where appropriate, from an interdisciplinary perspective, and how the fields may intersect with fields in related disciplines.

1f) the ability to apply learning from one or more areas outside the discipline

5) Awareness of Limits of Knowledge: ... an understanding of the limits of their own knowledge and abilities and an appreciation of the uncertainty, ambiguity and limits to knowledge and how this might influence analyses and interpretations.

A review of the CEAB accreditation requirements will confirm that these are covered as inputs in 3.3.4.2 "in addition to program specific engineering science, the curriculum must include engineering science

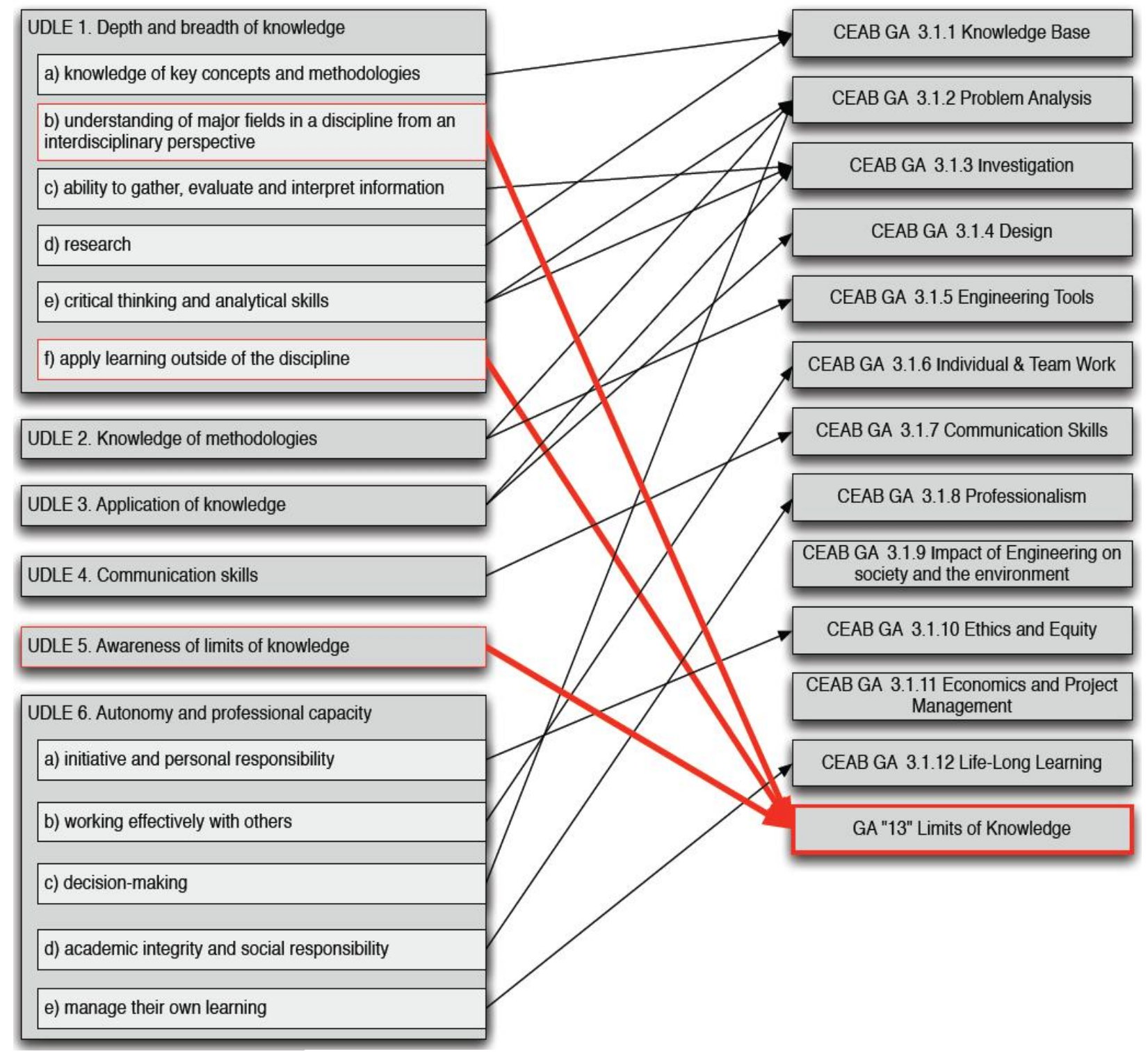

Figure 2. Graduate attribute and UDLE mapping 
content that imparts an appreciation of the important elements of other engineering disciplines.” [2]

We would like to assess this material as an output; which is why we created a thirteenth attribute:

13. Limits of Knowledge: An ability to appreciate important elements of other engineering disciplines and the limits of the graduate's own knowledge. See Figure 2 for this mapping.

\subsection{Competencies}

Our second area of attention has been on defining attributes and competencies. It will be beneficial to break down each of our thirteen attributes into competencies.

A competency, as defined by Joshua Earnest, is "a statement which describes the integrated demonstration of a cluster of related knowledge, skills and attitudes that are observable and measurable, necessary to perform a task independently at a prescribed proficiency level." [8]

Our main goal in breaking down the attributes into competencies is clarity, as the attributes are necessarily general and vague. Attributes are also not easily measurable. To show that graduates have certain attributes, we must be able to measure the attributes. Therefore, we are endeavouring to create measurable competencies that represent the attributes. This will be useful for curriculum change. A competency must clearly define a measurable area of knowledge, specify expectations in terms of cognitive levels, and be applicable to each discipline.
Most of the proposed competency definitions that we reviewed implied expectation levels in their definitions, making it challenging to clearly apply a common competency across disciplines with different expectation levels.

There are three parts to each of our competencies: area of knowledge, expectation levels, and context. Not breaking each competency down into three parts can lead to confusion.

To illustrate our process, consider a competency worded like this: "To be able to draw mechanical objects using proper drafting techniques." This competency includes a verb, which implies a cognitive level; "to be able to draw" is at level three on the revised Bloom's Taxonomy. This competency also specifies "mechanical objects" which makes it not applicable to all areas.

The area of knowledge is a noun phrase that clearly describes the specific aspect of the graduate attribute to be measured. There is no verb included here because a verb would imply a cognitive level.

There should be two expectation levels for each competency. Graduate attributes are descriptors of the graduating class, and not of individuals; therefore they do not specify minimum path. However, we want all students to achieve at least the minimum; the threshold. The threshold level is the minimum level at which all students must perform. The target level is a higher level at which a certain percentage of students are expected to perform. The thresholds and targets are specified in terms of a cognitive hierarchy, the revised Bloom's Taxonomy. In revising several

Table 1. Possible engineering tools competencies

\subsubsection{Engineering Tools}

\begin{tabular}{|c|c|c|c|c|}
\hline & Knowledge Area & Context & Threshold & Target \\
\hline 1 & $\begin{array}{l}\text { Diagrams and } \\
\text { engineering sketches }\end{array}$ & & To be able to label ___ (1) & To be able to draw __ (3) \\
\hline 2 & $\begin{array}{l}\text { Document- } \\
\text { processing and } \\
\text { graphics packages }\end{array}$ & & To be able to differentiate & To be able to classify ___ (4) \\
\hline 3 & $\begin{array}{l}\text { Tools for analysis, } \\
\text { simulation and } \\
\text { visualization }\end{array}$ & & To be able to adapt ___ (3) & To be able to appraise \\
\hline 4 & $\begin{array}{l}\text { Information from } \\
\text { relevant publications }\end{array}$ & & To be able to describe ___ (1) & To be able to verify ___ (5) \\
\hline 5 & $\begin{array}{l}\text { Limitations of such } \\
\text { tools and the } \\
\text { assumptions inherent } \\
\text { in their use }\end{array}$ & & To be able to interpret & To be able to measure ___ (5) \\
\hline
\end{tabular}


cognitive hierarchies, or learning taxonomies, it became clear that the revised Bloom's is most appropriate for our use, as the terms used are verbs and the highest level is "creating”.

Including a context component allows each discipline to specify a potentially unique area of application. At institutions with multiple programs, there will be a need to control the number of competencies. This is why it is important to keep the area of knowledge distinct from the level of expectation. In preparing the competencies this way for assessment, it becomes possible to have them apply across different disciplines, simply by altering the context, if necessary. See Table 1 for an example of a graduate attribute broken down into competencies.

\section{Conclusion}

The introduction of "Graduate Attributes" as a new requirement for accreditation requires careful consideration and extensive effort, and should result in continually improving engineering education.

In combining the graduate attributes with the OCAV UDLEs and creating a thirteenth attribute, we are more efficiently able to ensure that our programs meet the requirements.

Splitting the graduate attributes into competencies allows us to measure the attributes more easily. We are proposing that each competency contain three parts: area of knowledge, expectation levels, and context. The area of knowledge is simply a noun phrase, and does not contain a verb, which may imply a cognitive level. The expectation levels are a separate part of the competency. Each competency specifies a threshold (minimum) and a target, based on a cognitive hierarchy; the revised Bloom's Taxonomy. Finally, the context portion of each competency allows for a straightforward way to distinguish competencies for different disciplines.
These advancements that we have made should streamline our process in meeting the requirements for Graduate Attributes.

\section{References}

[1] Engineers Canada. "Canadian Engineering Accreditation Board." Internet:

www.engineerscanada.ca/e/pr_accreditation.cfm, [Mar. 21, 2011].

[2] Engineers Canada. CEAB Accreditation Criteria and Procedures. Ottawa, On, 2008.

[3] Accreditation Board for Engineering and Technology. The 2009 ABET Annual Report. Baltimore, MD, 2009.

[4] Engineers Australia. "Program Accreditation." Internet: www.engineersaustralia.org.au/about-us/programaccreditation/program-accreditation_home.cfm, [May 2, 2011].

[5] Engineering Accreditation Board. "Regulations for Registration.” Internet: www.engab.org.uk/documentation, [May 2, 2011].

[6] Ontario Universities Council on Quality Assurance. "Quality Assurance Framework.” Internet: www.cou.on.ca/Related-Sites/The-Ontario-UniversitiesCouncil-on-Quality-Assura/Policies/PDFs/QualityAssurance-Framework-and-Guide-Nov--2010.aspx, [Apr. 18, 2011].

[7] York University. "Why do we need Degree Level Expectations?” Internet: degreeexpectations.apps01.yorku.ca/wordpress/developing-degreelevel-expectations-for-your-unit-ocav-guidelines/why-dowe-need-degree-level-expectations/, [Nov. 1, 2010]. [8] J. Earnest. “ABET Engineering Technology Criteria and Competency Based Engineering Education,” presented at the $35^{\text {th }}$ ASEE/IEEE Frontiers in Education Conference, Indianapolis, Indiana, 2005.

[9] M. Carter. “A Process for Establishing Outcomes-Based Assessment Plans for Writing and Speaking in the Disciplines.” Internet: wac.colostate.edu/llad/v6n1/carter.pdf, [Nov. 1, 2010] [10] B. Frank. "Graduate Attribute Assessment Workshop," presented at Concordia University, Feb. 4, 2011. Internet: engineering.queensu.ca/egad/Resources_new.php, [Mar. 21, 2010]. 